\title{
A ESPECIFICIDADE DO ESTÉTICO E A RAZÃO PRÁTICA EM SCHILLER
}

\author{
Ricardo Barbosa* \\ ricjcb@uerj.br
}

RESUMO $O$ presente trabalho examina um problema recorrente no pensamento de Friedrich Schiller: o da unidade da razão na autonomia das formas fundamentais da racionalidade. Ele é analisado aqui no contexto da correspondência de Schiller com o Príncipe de Augustenburg em 1793 e do ensaio "Sobre a utilidade moral dos costumes estéticos". O propósito do trabalho é discutir esse problema desde a perspectiva do nexo entre a esfera estética e a razão prática. Segundo Schiller, o gosto seria uma condição necessária da liberdade.

Palavras-chave Schiller, Kant, Estética, Razão Prática

ABSTRACT This paper examines a recurrent problem in Friedrich Schiller's thinking: the unity of reason in the autonomy of the main forms of rationality. It is here analyzed in the context of Schiller's correspondence with the Prince of Augustenburg in 1793 and of the essay "The Moral Utility of Aesthetic Manners". The purpose of the paper is to discuss this problem from the perspective of the connection between the aesthetical sphere and the practical reason. According to Schiller, taste would be a necessary condition of freedom.

Key-words Schiller, Kant, Aesthetic, Practical Reason

* Professor do Departamento de Filosofia da Universidade do Estado do Rio de Janeiro. Artigo recebido em 15/09/05 e aprovado em 15/11/05.

KRITERION, Belo Horizonte, $\mathbf{n}^{\circ}$ 112, Dez/2005, p. 229-242 
O problema da unidade da razão na autonomia das formas fundamentais da racionalidade — a teórica, a prática e a estética — é um dos motivos centrais do pensamento de Friedrich Schiller. Embora este motivo seja de proveniência kantiana, Schiller não hesitou em voltá-lo contra Kant, como veremos, e mesmo contra Fichte. ${ }^{1}$ No que se segue, gostaria de colocar em evidência um aspecto do seu desenvolvimento - o da relação entre a especificidade do estético e as exigências da razão prática — , analisando-o à luz do ensaio "Sobre a utilidade moral dos costumes estéticos". ${ }^{2}$ Ele remonta à correspondência entre Schiller e o Príncipe de Augustenburg ao longo de 1793 e, portanto, à primeira versão das cartas Sobre a educação estética do homem (1794-1795).

No centro do problema dos “costumes estéticos", como a própria expressão já o sugere, está a pergunta sobre se e em que sentido o gosto é não só capaz de promover a moralidade, como também de prejudicar sua realização. Como registra a correspondência com Christian Gottfried Körner, em outubro de 1793 Schiller pensava em se haver com esse problema em um artigo sobre a sociabilidade estética — der ästhetische Umgang. ${ }^{3}$ De certo modo, esse escrito daria continuidade a "Sobre graça e dignidade", editado por Göschen poucos meses antes; portanto, era natural que Schiller desejasse vê-lo publicado pelo mesmo editor já no ano seguinte. Àquela altura, porém, o principal "interlocutor" de Schiller era o seu mecenas, o Príncipe de Augustenburg, com quem iniciara uma correspondência sobre questões estéticas em fevereiro daquele ano - 1793. Por essa circunstância, as idéias que pensara para o trabalho sobre a sociabilidade estética foram em parte desenvolvidas nas duas cartas ao Príncipe escritas em dezembro e em dois artigos: "Sobre o perigo dos costumes estéticos" e "Sobre a utilidade moral dos costumes estéticos". Publicados respectivamente nos números de novembro de 1795 e de março de 1796 de Die Horen, ambos foram frutos de uma temporada em Ludwigsburg: o primeiro, do outono; o segundo, do inverno de 1793. A rigor, "Sobre a utilidade moral dos costumes estéticos" corresponde, com poucas modificações, ao texto da carta de 3 de dezembro ao Príncipe de Augustenburg (NA 26, p. 322-333), da qual Schiller suprimiu, além das alusões pessoais, os dois primeiros e os quatro últimos parágrafos.

BARBOSA. Schiller e a cultura estética, p. 46-47.

2 Uma tradução desse artigo encontra-se em BARBOSA. Schiller e a cultura estética, p. 55-67.

3 Cf. carta de Schiller a Körner, Ludwigsburg, 4 de outubro de 1793, em: SCHILLER. Schillers Werke. Nationalausgabe, Bd. 26, Schillers Briefe 1. 3. 1790 - 17. 5. 1794, p. 289. As demais citações da Nationalausgabe serão feitas no corpo do texto pela abreviatura $N A$, seguida do número do volume e da página. 
O primeiro parágrafo dessa carta anuncia a questão central acerca do nexo entre o estético e a razão prática: "Tenho a responder a pergunta sobre quanto a virtude ganha através do gosto" (NA 26, p. 322, grifo no originial). Seja em suas preleções de estética do semestre de inverno de 1792-1793, seja na correspondência com Körner em janeiro e fevereiro de 1793 sobre o problema do fundamento objetivo do belo, seja nos diversos escritos sobre o trágico, o sublime e o patético, como também em "Sobre graça e dignidade" e, naturalmente, na correspondência com o Príncipe de Augustenburg, Schiller ocupou-se, de diferentes maneiras, com o nexo entre o estético e a razão prática, mas sempre em confronto direto ou indireto com Kant. Como se lê no segundo parágrafo da carta citada, Schiller se declarava "inteiramente kantiano" quanto ao "ponto principal da doutrina dos costumes" — ou seja, a tese segundo a qual uma ação só pode ser considerada como moral se fundada no "respeito à lei da razão" e não as inclinações (NA 26, p. 322). Ao mesmo tempo, Schiller reagia implicitamente aos comentários que Kant fizera a propósito de "Sobre graça e dignidade", em uma longa nota de pé de página à segunda edição de $A$ religião nos limites da simples razão, preparando-se para defender a utilidade moral dos costumes estéticos contra os traços ascéticos da ética kantiana.

Embora tenha suprimido os dois primeiros parágrafos dessa carta quando a revisou para publicação, Schiller não recuou diante de sua divergência com Kant. Acenando para a continuidade de suas reflexões sobre o nexo entre o estético e a razão prática, ele abria o artigo referindo-se ao trabalho "Sobre o perigo dos costumes estéticos", recentemente publicado, pois pretendia agora destacar a outra face do problema, já indicada no título que escolhera: a utilidade moral dos costumes estéticos. Segundo a tese do artigo anterior, o perigo dos "costumes estéticos" se afigura sempre que a vontade se deixa determinar pelo gosto. Com isso, Schiller chamava a atenção para uma forma específica de heteronomia da vontade. Essa forma de heteronomia seria um derivado perverso de uma legítima exigência do gosto: a de que a razão e a sensibilidade se afinem pela clave do prazer livre e desinteressado. Assim harmonizadas, pode também surgir o perigo de que esse livre acordo entre elas resulte na deposição da razão pela imaginação precisamente na esfera em que aquela deve legislar sem contrastes: a esfera da ação moral.

A tese central de "Sobre a utilidade moral dos costumes estéticos" (NA 21, p. 28-37) é a contraface do argumento de "Sobre o perigo dos costumes estéticos": embora o gosto não possa "produzir algo de moral através de sua influência", pois a razão prática não pode ter como base o sentimento da beleza, ele ainda assim é capaz de "favorecer a moralidade" (NA 21, p. 28, grifo no original). Diga-se de passagem que Schiller não faz aqui nenhuma distinção 
entre a eticidade (die Sittlichkeit), o ético (das Sittliche) e a moralidade (Moralität), ou entre o sentimento da beleza (Schönheitsgefühl) e o gosto (Geschmack). Pois bem, o gosto pode favorecer a moralidade, esta é a tese de Schiller; mas é preciso mostrar como ele pode fazê-lo.

\section{II}

Schiller distingue entre a liberdade física e a liberdade moral. Pela primeira, simplesmente seguimos a nossa vontade; pela segunda, determinamos racionalmente a nossa vontade. Sob ambos os aspectos, a possibilidade de agir livremente pode dever-se a um fundamento externo: a simples ausência de obstáculos. É nesse sentido que se diz que alguém recebeu a liberdade de um outro, embora se saiba que a liberdade implica a independência de toda determinação alheia. No entanto, lembra Schiller, é também nesse sentido que se diz que o gosto pode favorecer a virtude, embora a virtude não possa ser dada ou recebida. Em suma, quando contribui para eliminar obstáculos que impedem a determinação racional da vontade, o gosto pode favorecer a moralidade como o seu fundamento externo.

A mera ausência de obstáculos não desqualifica uma ação fisica ou moralmente livre, pois o fundamento tanto de uma quanto de outra não é externo. Mas a existência de obstáculos pode impor dificuldades às ações, pelo que existem "graus de liberdade" e "graus de moralidade" de acordo com os quais a vontade e a razão fazem valer seu poder de determinação perante forças contrárias. Uma ação moralmente correta é aquela que é realizada pura e simplesmente porque é moral, e não porque é agradável, ou seja, pela gratificação sensível que pode proporcionar. A imoralidade efetiva resulta, pois, da "colisão do bom com o agradável", "da apetição com a razão", assim como a sua fonte se encontra seja na "força dos impulsos sensíveis", seja na "fraqueza" da "vontade moral" (NA 21, p. 30).

A moralidade pode ser promovida (ou impedida) de dois modos: pelo fortalecimento da razão e da vontade moral (contra a força dos impulsos sensíveis) ou pelo enfraquecimento do poder das tentações (a favor de uma razão e de uma vontade moral ainda fracas). Embora esta segunda via não incida diretamente sobre a vontade moral, mas sobre o que pode enfraquecêla, isto não chega a comprometer a moralidade da ação, pois não se trata aqui de uma má vontade, e sim apenas de uma boa vontade ainda fraca. Daí o princípio enunciado por Schiller neste passo: "aquilo que promove verdadeiramente a moralidade é o que aniquila a resistência da inclinação contra o bom" (NA 21, p. 30). 
Ao falar em graus de liberdade e em graus de moralidade, Schiller se afasta da doutrina kantiana no mal radical, da qual, aliás, nunca esteve convencido. Já em sua correspondência com Körner sobre o projeto de Kallias, Schiller se manifestara contra aquela convicção de Kant, ${ }^{4}$ assim como o faria novamente na carta a Goethe de 2 de agosto de 1799, na qual deplora o tratamento "demasiadamente monástico" dispensado por Kant à relação entre a vontade livre e a matéria:

nunca pude ser reconciliado com isso. Todo o seu fundamento de decisão baseia-se em que o homem tem um impulso positivo para o bem, assim como para o bem-estar sensível; portanto, se ele escolhe o mal, também precisa de um fundamento positivo interno para o mal, pois o positivo não pode ser superado por algo meramente negativo. Aqui, porém, duas coisas infinitamente heterogêneas, o impulso para o bem e o impulso para o bem-estar sensível, estão tratadas inteiramente como potências e quantidades iguais, pois a personalidade livre é colocada igualmente contra e entre ambos os impulsos (NA 30, p. 77).

Pouco antes, e também em carta a Goethe, de 21 de dezembro de 1798, na qual se dizia "ansioso" para ler a Antropologia de Kant, já que nela o "lado patológico" do homem, recorrente em seus escritos como o motivo, que "dá à sua filosofia prática um aspecto tão rabugento", talvez encontrasse o seu lugar, Schiller afirmaria que em Kant, "como em Lutero", haveria algo que "lembra um monge que, na verdade, abriu seu mosteiro, mas não pôde exterminar totalmente os vestígios do mesmo" (NA 30, p. 15). Para Schiller, o "mal" consistia no predomínio do impulso sensível, e não em uma disposição natural humana. O impulso sensível, cuja exigência de satisfação tende a se impor incondicionalmente sobre a vontade, é o "inimigo interno natural da moralidade", o antagonista da razão e das leis morais, sob as quais deve estar a vontade (NA 21, p. 30).

A vontade é, assim, o cenário de um conflito entre o impulso sensível e a determinação racional. Um ânimo rude, carente de formação moral e estética, é dominado pela apetição, pelas exigências do impulso sensível. Um ânimo moral, mas carente de formação estética, age em conformidade com a lei da razão e por ela supera resistências e tentações. Já os ânimos "esteticamente refinados" contam com um diferencial: o gosto, capaz de fazer as vezes da virtude ou de facilitá-la.

"Moderação e decoro", aversão ao que é "anguloso, duro e violento", receptividade ao que é composto com "leveza e harmonia": eis as exigências

4 SCHILLER. Kallias ou sobre a beleza. A correspondência entre Schiller e Körner, janeiro e fevereiro de 1793, p. 108-109. 
do gosto (NA 21, p. 31). O gosto é um traço do homem civilizado, capaz de conter os rudes impulsos sensíveis, observando o "bom tom" como uma "lei estética" (NA 21, p. 31). Como sabe conter a manifestação dos seus sentimentos, pode também dominá-los, dispondo assim da capacidade de romper com a passividade de sua alma pela auto-atividade e de introduzir a reflexão na passagem dos sentimentos à ação. Este domínio sobre a natureza e seus impulsos, embora não engendre a virtude, cria condições favoráveis para o cultivo racional da vontade; como diz Schiller, ele "abre espaço para a vontade voltar-se para a virtude" (NA 21, p. 31). Schiller admite que, através do gosto, a vontade acede a uma forma peculiar de liberdade. Embora ainda não a chame de liberdade estética, como só o fará nas cartas Sobre a educação estética do homem, ela não se confunde com a liberdade moral. Mas enquanto "liberta o ânimo do jugo do instinto", neutralizando assim a ação do antagonista da liberdade moral, o gosto pode se revelar como um novo inimigo, tanto mais sutil quanto melhor se apresente "sob a capa de amigo", pois também o gosto é movido pelo prazer (NA 21, p. 32). Ainda que este prazer seja nobre, porque radicado na razão, ele não pode fundar a moralidade, já que esta exclui a determinação da vontade pelo prazer.

Para um ânimo esteticamente cultivado não bastam apenas as inclinações sensíveis. O gosto refinou suas exigências, tornando o ânimo afeito a inclinações "mais nobres e mais suaves", para desejos de "ordem", "harmonia", "perfeição". Tais inclinações não são virtudes, mas "partilham um objeto com a virtude"; pois se, por um lado, o gosto é vigilante quando o apetite toma a palavra, por outro, quando a razão exige ordem, harmonia e perfeição nas ações, conta com a aprovação, e não com a resistência, da inclinação (NA 21, p. 32). Daí os dois modos pelos quais a eticidade pode se manifestar: com ou sem a mediação dos sentidos. No primeiro caso, a moção de que algo aconteça, ou não aconteça, é feita ao ânimo pela sensibilidade e é julgada pela vontade de acordo com a lei da razão; no segundo, a moção é feita diretamente pela razão, sem a mediação dos sentidos, cabendo à vontade obedecer a ela.

Estes dois modos de manifestação da eticidade são considerados por Schiller mediante dois exemplos. O primeiro, que remonta aos Acontecimentos memoráveis da vida do Imperador grego Alexis Komnenos, da princesa grega Anna Komnena, apresenta a situação de um prisioneiro que, a caminho da morte, vê-se tentado a assassinar o general que o escolta, mas resiste a esta tentação. O segundo relembra o feito heróico do Duque Leopold von Braunschweig, que não hesitou em lançar-se nas águas caudalosas do Oder para tentar salvar, sem sucesso e ao preço da própria vida, as vítimas de uma terrível inundação. Ambos agiram moralmente; ambos submeteram a vontade 
à razão, embora o Duque tenha tido de vencer o impulso de autoconservação pela consciência do dever.

Estes mesmos exemplos são também considerados sob a hipótese de como o prisioneiro e o Duque teriam agido se o gosto tivesse desempenhado algum papel em suas decisões. No primeiro caso, se se admite que o condenado à morte resisitira a ganhar a própria liberdade pelo assassinato do seu guardião, não por respeito à justiça, mas por força de um sentido estético incapaz de tolerar gestos infames e violentos, sua decisão não teria sido tomada no plano do sentimento, não no da consciência moral. Sua ação seria conforme à lei, mas "moralmente indiferente": enraizada no sentimento, apresentar-se-ia como "um mero efeito belo da natureza" (NA 21, p. 34). Se se admite que o segundo também tivesse um gosto apurado e afeito aos grandes gestos, então a razão e a sensibilidade teriam se unido como uma única força: ele teria feito valer o dever com, e não contra, a inclinação. $\mathrm{O}$ fato de que ele teria respeitado a prescrição da razão com alegria não comprometeria a "pureza ética" de sua ação: ela seria moralmente perfeita e fisicamente ainda mais perfeita, pois revelaria um ânimo inteiramente adequado à virtude.

Eis porque Schiller defende o gosto como um poderoso aliado da virtude: ele filtra as inclinações, dando livre curso apenas àquelas que lhe são favoráveis. Como foi visto, ele pode ser útil à moralidade de duas maneiras. Enquanto instância de decisão da ação, conforma feitos muito mais moralmente indiferentes do que verdadeiramente morais. Porém, Schiller adverte que a "excelência dos homens" não está "na maior soma de ações rigorístico-morais isoladas, e sim na maior congruência de toda a disposição natural com a lei moral" (NA 21, p. 34, grifo no original). E o que vale para os homens individualmente, argumentava Schiller, vale também para povos e épocas inteiras. A freqüência com que se fala da moralidade e de feitos morais individuais seria, segundo ele, um sintoma de debilidade cultural. Uma cultura desejável seria aquela na qual simplesmente não mais se falasse sobre isto. Por outro lado, os costumes estéticos adquirem uma utilidade positiva quando vêm em socorro ao apelo da razão contra as ameaças dos impulsos naturais. O gosto então "harmoniza nossa sensibilidade em proveito do dever", impedindo que mesmo uma vontade moral mais fraca resulte aquém da virtude (NA 21, p. 35).

\section{III}

Se se admite que o gosto não representa nenhum obstáculo para a moralidade, que inclusive favorece a legalidade das nossas ações, então é preciso extrair as conseqüências desta afinidade entre o estético e o moral. Em 
uma palavra: tais consequiências resultam da tomada de consciência da unidade do físico e do espiritual, do natural e do moral. Enquanto o forum moral exige que nossas ações decorram de nossas convicções, o forum físico requer que elas favoreçam o fim da natureza. No entanto, as ordens moral e física formam uma unidade tal que a conformidade a fins moral de uma ação em sua forma corresponde à conformidade a fins física em seu conteúdo, pelo que Schiller distingue o bem como sendo, ao mesmo tempo, o fim supremo possibilitado pela natureza e um meio para a manutenção da ordem natural. A unidade das ordens moral e física é tal que a violência que se faz a uma recai sobre a outra.

Schiller era suficientemente "realista" para admitir que seria ingênuo esperar que a conduta humana se orientasse imperturbavelmente pelo norte da virtude. Atento à vulnerabilidade das ordens moral e física, assim como ao vínculo delicado que as une, Schiller insistia em que ao menos as exigências da natureza fossem satisfeitas pelas nossas ações. Com isso, certamente permanecíamos em débito para com a razão, mas não para com o fím da natureza, do qual teríamos sido "instrumentos perfeitos" (NA 21, p. 36). Face à contingência da virtude, é preciso garantir ao menos a legalidade das ações humanas como condição necessária ao impedimento da desagregação social. Schiller não poderia ter sido mais enfático na escolha de um exemplo expressivo dessa situação de risco. Como o louco que, na iminência de uma crise, se afasta de tudo que possa usar contra a sua própria integridade, chegando mesmo a pedir que o imobilizem, pois assim evitaria os males que poderia causar e pelos quais seria responsabilizado, nossa natureza vulnerável carece da religião e das "leis estéticas" como algo que nos ate e assim impeça que nossas paixões, uma vez descontroladas, violem a ordem física.

Se a religião e o gosto figuram aqui no mesmo plano, é porque ambos estariam em condições de produzir um efeito moral: como substitutos da "verdadeira virtude", poderiam ao menos "assegurar a legalidade onde não se é de esperar a moralidade" (NA 21, p. 36). Como se vê, Schiller determina a utilidade moral (e o perigo) dos costumes estéticos segundo a distinção entre moralidade e legalidade formulada na Crítica da razão prática:

O essencial de todo o valor moral das ações depende de que a lei moral determine imediatamente a vontade. Se a determinação da vontade acontece conforme a lei moral, mas apenas mediante um sentimento, seja ele de que tipo for, que tem de ser pressuposto para que aquele se torne um fundamento de determinação suficiente da vontade, portanto, não por causa da lei, então a ação conterá legalidade, mas não moralidade. ${ }^{5}$

5 KANT. Kritik der praktischen Vernunft. In: Werke, v. 6, A 126-127. (grifos no original). 
Os costumes estéticos seriam, então, moralmente úteis de um duplo modo: indiretamente, enquanto promovem a legalidade, pois, nesse caso, estamos diante de ações cujo fundamento de determinação é sensível, embora exibam uma similaridade à moral; diretamente, enquanto se trata de ações conformes à moral tanto na forma quanto no conteúdo, pois, nesse caso, a determinação da vontade não se dá ao preço do recalque das inclinações, mas à base da aliança — promovida pelo gosto - entre a razão e a sensiblidade. Aquele que não carece nem do gosto, nem da religião, nem do "atrativo da beleza", nem da "perspectiva de uma imortalidade" para agir em conformidade ao dever, dizia Schiller, desfrutaria de "uma alta posição na categoria dos espíritos"; mas a vulnerabilidade humana nos obriga — inclusive ao "mais rígido ético" (e Schiller se dirige aqui a Kant) - a ser rigorosos na teoria e prudentes em sua aplicação, de modo que o bem da humanidade, sempre ameaçado pela contingência da virtude, seja assegurado, uma vez ancorado na religião e no gosto (NA 21, p. 37).

No entanto, esse nivelamento da religião e do gosto não significa que ambos poderiam substituir a virtude em igualdade de condições, como adverte Schiller nos quatro últimos parágrafos de sua carta ao Príncipe de Augustenburg, suprimidos em sua versão impressa como artigo.

Onde nenhuma cultura estética abriu o sentido interno e aquietou o sentido externo, e as nobres sensações do entendimento e do coração ainda não limitaram as necessidades comuns dos sentidos, ou na situação em que também o maior refinamento do gosto não pode impedir o impulso sensível de insistir numa satisfação material — aí está a religião, que também indica ao impulso sensível um objeto e the assegura uma indenização pelas vítimas que ele faz à virtude, aqui ou ali. (...) A religião é para o homem sensível o que o gosto é para o refinado, o gosto é para a vida habitual o que a religião é para a extremidade. Num destes dois apoios, quando não de preferência em ambos, temos porém de nos manter, na medida em que não somos deuses (NA 26, p. 331-332, grifo no original).

Como se vê, a utilidade moral da religião só se faz sentir onde a cultura estética ainda não penetrou e se fez valer como a autêntica formadora do homem moderno. Não é casual que Schiller observasse entre a religião e o gosto uma assimetria na qual se refletiam os antagonismos sociais e, ao mesmo tempo, funções culturais e políticas similares. Afinal, se a religião estaria para as massas como "o contrapeso dos seus padecimentos", o gosto seria para as "classes mais refinadas" uma garantia da "conformidade à lei da conduta" (NA 26, p. 333). O ideal da cultura estética, pelo que se depreende da correspondência de Schiller com o Príncipe de Augustenburg, seria não apenas a superação da religião como a tradicional força histórico-cultural de formação do homem, especialmente das massas, como também um incremento do gosto tal que o 
seu poder formativo não mais se restringisse às classes dominantes nem se limitasse à condição de promotor indireto da moralidade, ao que pesasse todo o sóbrio realismo de Schiller em face da natureza humana.

Schiller não se voltou para o problema da "cultura estética" e da "educação estética do homem" apenas motivado pela possibilidade de retomar a reflexão sobre as condições da "teoria da arte" como "uma ciência filosófica" (NA 26, p. 185) a partir do ponto em que Kant a deixara ao excluir de sua tarefa as questões relativas à formação e à cultura do gosto. ${ }^{6}$ Ele estava convencido da necessidade de enfrentar essas questões justamente porque via nos desdobramentos da Revolução Francesa uma ameaça ao ideal histórico da revolução burguesa: a instituição da liberdade. Essa preocupação, explicitamente declarada em sua correspondência com o Príncipe de Augustenburg, seria consumada em Sobre a educação estética do homem, cuja tese central é lançada ao final da segunda carta: "deixando que a beleza preceda a liberdade (...) mostrarei que para resolver na experiência o problema político é necessário caminhar através do estético, pois é pela beleza que se vai à liberdade." O "problema político" ao qual Schiller se referia era justamente o da realização do ideal histórico da revolução burguesa, recalcado pela avalanche do terreur. É precisamente isso o que explica o fato de Schiller não desprezar, ao lado da utilidade moral dos costumes estéticos, a utilidade moral da própria religião. Afinal, dizia ele ao Príncipe, a Revolução teria, em um único golpe, desterrado a religião e abandonado o gosto à "selvageria" — um golpe tanto mais funesto quanto mais o "caráter da nação" carecia justamente dessas ancoras sensíveis (NA 26, p. 333).

Arbitrariedades como essa adensavam em Schiller a convicção de que as ilusões políticas nascidas naquela hora histórica demandariam tempo e muitos esforços para serem desfeitas.

Fosse verdadeiro o fato - tivesse ocorrido realmente o caso extraordinário de que a legislação política fora confiada à razão, de que o homem fora respeitado e tratado como um fim em si mesmo, de que a lei fora elevada ao trono e a verdadeira liberdade tornada em fundamento do edifício do Estado, então queria despedir-me eternamente das musas e dedicar toda minha atividade à mais magnífica de todas as obras de arte, à monarquia da razão. Mas este fato é justamente o que ouso por em dúvida. Sim, estou tão longe de crer no início de uma regeneração no âmbito político, que os acontecimentos da época antes me tiram por séculos todas as esperanças disso ( $N A$ 26, p. 262).

6 KANT. Kritik der Urteilskraft. In: Werke, v. 8, B IX

7 SCHILLER. A educação estética do homem, p. 26. 
E, após uma dura crítica à Aufklärung - a cujo princípio, no entanto, não renunciava -, aos destinos da Revolução Francesa, à miséria em que viviam as classes populares e à lassidão das "classes civilizadas", Schiller expressava seu ceticismo diante das promessas de liberdade vazadas em uma constituição de Estado carente das bases de uma Sittlichkeit, cuja desejada existência jamais poderia prescindir do poder formador do gosto.

Se me é pois permitido, Magnânimo Príncipe, dizer minha opinião sobre as expectativas e necessidades políticas do presente, confesso que considero extemporânea toda tentativa de uma constituição de Estado a partir de princípios (pois qualquer outra é mera obra de emergência e remendo), e como quimérica toda esperança nela fundada, até que o caráter da humanidade tenha sido novamente elevado de sua profunda decadência - um trabalho para mais de um século (NA 26, p. 264).

A tarefa da "cultura estética", pouco depois formulada nos termos de uma "educação estética" do homem, seria justamente a de criar as condições subjetivas para a instituição da liberdade. Se essa exigência permanecia viva, era porque a hora de sua realização não encontrara uma humanidade à sua altura, como se lê no xênio "O momento": "O século deu à luz uma grande época, / Mas o grande momento encontra uma pequena estirpe" (NA 1, p. 313).

\section{IV}

Em Sobre a educação estética do homem, Schiller já não mais apelaria à utilidade moral do sentimento religioso, confiando inteiramente ao gosto a tarefa formativa da personalidade individual e do caráter do povo. No entanto, numa carta a Goethe de 17 de agosto de 1795, Schiller reconheceria na idéia do cristianismo - e não em suas "diversas manifestações na vida", tão "insípidas e adversas" à luz de sua destinação ideal — uma exigência mais nobre que aquela presente na ética kantiana.

Se nos ativermos ao traço de caráter próprio do cristianismo, que o distingue de todas as religiões monoteístas, veremos que ele não se encontra em nada mais senão na superação da lei ou do imperativo kantiano, em cujo lugar o cristianismo quer ter colocado uma livre inclinação. Ele é, pois, em sua forma pura, a apresentação da bela eticidade e da encarnação do sagrado e, nesse sentido, a única religião estética (...) (NA 28, p. 27-28).

Esse juízo, que se qualifica ao mesmo tempo como uma crítica contundente ao cristianismo histórico e como um importante reparo à ética kantiana, remete a uma distinção já estabelecida em Kallias — e justamente no contexto nada casual de uma reformulação profana da parábola do bom samaritano: a distinção 
entre uma ação moralmente boa e uma ação moralmente bela. A primeira, na qual a ética kantiana se consuma, corresponde à rigorosa determinação racional da vontade. Na segunda, a oposição entre a determinação racional e a inclinação sensível é suprimida no sentido mesmo em que Schiller vira a beleza como a liberdade no fenômeno; portanto, na ação moralmente bela, o elemento natural aparece como se fosse livre, na medida mesma em que a liberdade se apresenta como se fosse natureza. Em termos estritamente kantianos, o que é livre não pode ser uma inclinação, que é sempre sensível, assim como uma inclinação não pode ser livre, pois o que é livre é sempre racional. No entanto, na superação cristã do imperativo categórico vê-se justamente o ponto em que o moral e o estético, o natural e o livre se fundem - e por isso não uma simples inclinação, mas uma livre inclinação é postulada sem contradição.

Formulada na correspondência com Körner em torno do projeto de Kallias, essa concepção da beleza moral também figura em "Sobre graça de dignidade". Sua convergência com o imperativo ético cristão "em sua forma pura" salta aos olhos, especialmente em face do significado moral do amor no cristianismo, do que Schiller dissera sobre a nobreza dessa disposição humana:

A liberdade no fenômeno desperta não apenas o prazer pelo objeto, como também inclinação pelo mesmo; esta inclinação da razão de se unir com o sensível chama-se amor. Contemplamos o belo propriamente não com respeito, mas com amor; excluída a beleza humana, que, no entanto, encerra em si a expressão da eticidade como objeto do respeito. - Se devemos ao mesmo tempo amar o que é digno de respeito, então este tem de ser alcançado por nós ou ser alcançável para nós. O amor é uma fruição, mas não o respeito; trata-se aqui de tensão; lá, de relaxamento. - O prazer da beleza surge, pois, da analogia notada com a razão, e está unido ao amor. ${ }^{8}$

Tão ingênuo quanto supor que a ênfase nessa convergência entre a beleza moral e a ética do amor nos deva convencer de que os argumentos de Schiller a propósito da utilidade moral dos costumes estéticos resultem em uma apologia do imperativo ético cristão contra a moral kantiana seria crer que sua reivindicação dos direitos da sensibilidade se resuma a um discreto elogio de uma espécie de "moral de resultados", conformada a satisfazer-se com a mera legalidade das ações em face das exigências quase sobre-humanas de uma pura moral dos princípios, para não falar da santa nobreza dos poucos capazes de ações moralmente belas, como o bom samaritano ou Francisco de Assis. No entanto, não há dúvida de que Schiller, "inteiramente kantiano" muito mais segundo o espírito que a letra do idealismo transcendental, e, nesse sentido, em nome da exigência de que quanto maior o rigor teórico na fundamentação 
da moral, mais prudentes devemos ser em sua aplicação, parece ter tomado à risca um conhecido dito do próprio Kant: "de uma madeira tão retorcida, da qual o homem está feito, nada reto pode ser construído"...9

\section{V}

Schiller pensou o problema da unidade da razão simultaneamente sob dois aspectos: o da autonomia das formas fundamentais da racionalidade e o da permeabilidade dessas formas. Nos ensaios publicados em Die Horen depois do aparecimento das cartas Sobre a educação estética do homem, Schiller concentrou-se tanto nos nexos entre a esfera estética e a razão prática, como em "Sobre o perigo dos costumes estéticos" e "Sobre a utilidade moral dos costumes estéticos", quanto nos nexos entre aquela esfera e a razão teórica, como em "Dos limites necessários do belo particularmente na apresentação de verdades filosóficas", fruto de sua polêmica com Fichte no verão de 1795, posteriormente fundido com o ensaio sobre o perigo dos costumes estéticos e publicado no segundo volume dos Escritos menores em prosa (1800) sob o título "Sobre os limites necessários no uso das formas belas". No centro de todos esses escritos encontra-se o mesmo tipo de indagação: se e até que ponto pode o estético promover, ou prejudicar, seja a verdade, seja a moralidade. Em ambos os casos, o que está em jogo é um problema normativo, pois trata-se de estabelecer os limites do gosto e as condições sob as quais suas exigências, na medida em que resultam de um princípio que o funda como uma esfera autônoma, são permeáveis às exigências da verdade teórica e da correção prática, ambas radicadas em esferas igualmente autônomas.

À primeira vista, o problema da unidade da razão se afigura nesses ensaios como se a coordenação dos usos teórico, prático e estético da razão fosse a condição suficiente para a sua solução, em outras palavras, como se Schiller o tivesse tratado à maneira de Kant, mantendo-se assim distante de uma exigência que a Elementarphilosophie de Reinhold e, a seguir, a Wissenschaftslehre de Fichte, secundada pelo Schelling de Sobre a possibilidade de uma forma da filosofia em geral, tornariam, no imperativo da constituição da filosofia como ciência: a subordinação dos usos coordenados da razão a um princípio incondicionado. Essa impressão se dissolve por uma leitura atenta das cartas Sobre a educação estética do homem, o que me limito aqui a apenas deixar indicado. ${ }^{10}$ Mais que "o primeiro escrito programático para uma crítica estética

9 KANT. Idee zu einer allgemeinen Geschichte in weltbürgerlicher Absicht. In: Werke, v. 9, A 397.

10 BARBOSA. O surgimento de uma Elementarphilosophie estética a partir do espírito do idealismo transcendental. Sobre Schiller e Fichte, 2004. 
da modernidade", ${ }^{11}$ elas são a primeira tentativa de uma fundamentação estética do idealismo transcendental, na qual a problemática que deu origem ao chamado idealismo alemão, a do fundamento absoluto da razão, vista desde Reinhold como o principal déficit teórico da crítica kantiana, conheceu uma formulação ainda infensa ao pathos da identidade, dominante em Hölderlin e em Schelling. As reflexões de Schiller sobre os limites do belo, seja a propósito do perigo e da utilidade moral dos costumes estéticos, seja sobre a legitimidade do recurso a procedimentos estéticos na prosa filosófica, ${ }^{12}$ embora não se refiram explicitamente ao que ele, desde a primavera de 1794, em alusões ao manuscrito de Sobre a educação estética do homem, passara a chamar de seu "sistema", a sua "Elementarphilosophie", encontram aqui o diapasão pelo qual se afinam numa tonalidade que não mais seria ouvida.

\section{Referências}

BARBOSA, Ricardo. Schiller e a cultura estética. Rio de Janeiro: Jorge Zahar, 2004. . Verdade e beleza. Schiller e o problema da escrita filosófica. Revista de

Filosofia Seaf, Rio de Janeiro, n. 4, p. 16-37, 2004.

. O surgimento de uma Elementarphilosophie estética a partir do espírito do idealismo transcendental. Sobre Schiller e Fichte, 2004. (Mimeo.).

HABERMAS, Jürgen. Der philosophische Diskurs der Moderne. Frankfurt am Main: Suhrkamp, 1986.

KANT, Immanuel. Kritik der praktischen Vernunft. In: Werke. Ed. de Wilhelm

Weischedel. Darmstadt: Wissenschaftliche Buchgesellschaft, 1983. v. 6. . Kritik der Urteilskraft. In: . Werke. Ed. de Wilhelm Weischedel.

Darmstadt: Wissenschaftliche Buchgesellschaft, 1983. v. 8.

. Idee zu einer allgemeinen Geschichte in weltbürgerlicher Absicht. In: - Werke. Ed. de Wilhelm Weischedel. Darmstadt: Wissenschaftliche Buchgesellschaft, 1983. v. 9.

SCHILLER, Friedrich. Schillers Werke. Nationalausgabe. Weimar: Hermann Böhlaus Nachfolger, 1943-19??.

. Fragmentos das preleções sobre estética do semestre de inverno de 1792-

93. Tradução e introdução de Ricardo Barbosa. Belo Horizonte: Editora UFMG, 2004. . Kallias ou sobre a beleza. A correspondência entre Schiller e Körner, janeiro e fevereiro de 1793. Tradução e introdução de Ricardo Barbosa. Rio de Janeiro: Jorge Zahar, 2002.

- A educação estética do homem. Tradução de Roberto Schwarz e Márcio Suzuki. São Paulo: Iluminuras, 1990.

11 HABERMAS. Der philosophische Diskurs der Moderne, p. 59.

12 BARBOSA. Verdade e beleza. Schiller e o problema da escrita filosófica. Revista de Filosofia Seaf, n. 4, p. 16-37, 2004. 